\title{
DIRECT MEASUREMENT OF INTERNAL MOISTURE DEFICITS IN TREES ${ }^{1}$
}

\author{
BY GEOFFREY PIERPOINT²
}

Oxf. 161.1

\begin{abstract}
A technique for the direct measurement of xylem moisture pressure is reviewed and some original results are used as a basis for discussing certain facts relating to the use of the technique.

\section{INTRODUCTION}

It is well known that water is an essential constituent of living plants and that comparatively large quantities of water pass through them during the course of a growing cycle. As soil dries below field capacity, so the uptake of water by the plant roots becomes increasingly difficult and the internal moisture stress becomes greater, resulting in the closing of stomata, reduction of photosynthesis and growth, loss of turgor and ultimately death of the organs and the plant itself.

Although, in the past, workers have concerned themselves with soil moisture potential, air temperature and air humidity as parameters influencing the moisture stress which a plant is undergoing at anyi particular time, the measurement of these external factors has not indicated clearly the magnitude of the internal moisture stresses prevailing. Yet it is the internal moisture stress which is the significant parameter governing the functioning of a plant at a specific time.

Recently, a method was reported (Scholander et al. 1965) which makes possible the direct measurement of the internal moisture pressure of a plant, using a simple pressure vessel, or "bomb." The technique is here introduced to the forestry literature and some early results are given as a basis for discussion. Foresters in research or certain areas of management may find the method a useful tool.
\end{abstract}

\section{METHOD AND EquipMENT}

The method revolves round the principle that when a twig or branch is severed from the main tree, the water retracts a short way into the xylem of this severed portion until it hangs up on a cross wall, but may be forced back to the cut surface by the application of gas pressure on the foliage. The retraction of water occurs because the internal moisture pressure is negative, relative to atmospheric pressure. The positive gas pressure on the foliage required to bring the moisture just back to the cut surface equals numerically the negative moisture pressure. This positive gas pressure can be applied and measured relatively easily and accurately.

A plant pressure bomb apparatus (Figure 1) constructed by the Mechanical Section of the Research Branch comprises (i) the "bomb" itself, which is a piece of steel tubing with a welded-on base and a screw-on lid, sealed with an O-ning, (ii) a gas-tight gland (rubber bung), inserted in the lid, for holding

${ }^{1}$ Contribution No. 67-7, Research Branch, Ontario Department of Lands and Forests.

2 Research Scientist, Ontario Department of Lands and Forests, Maple, Ont. 
the tree portion in such a way that the cut end of the stem is protruding outside the bomb, and is thus at atmospheric pressure, whilst the remainder is inside the bomb, (iii) a gauge to measure the gas pressure inside the bomb, (iv) inlet and outlet valves for controlling gas pressures inside the bomb, and ( $v$ ) a high-pressure supply of nitrogen or air. The apparatus can be made relatively portable.

The operator selects and severs the portion of the tree whose internal moisture pressure he wishes to know, peels the bark and phloem off the cut stem of the twig for a short distance back from the cut, inserts the stem in the rubber

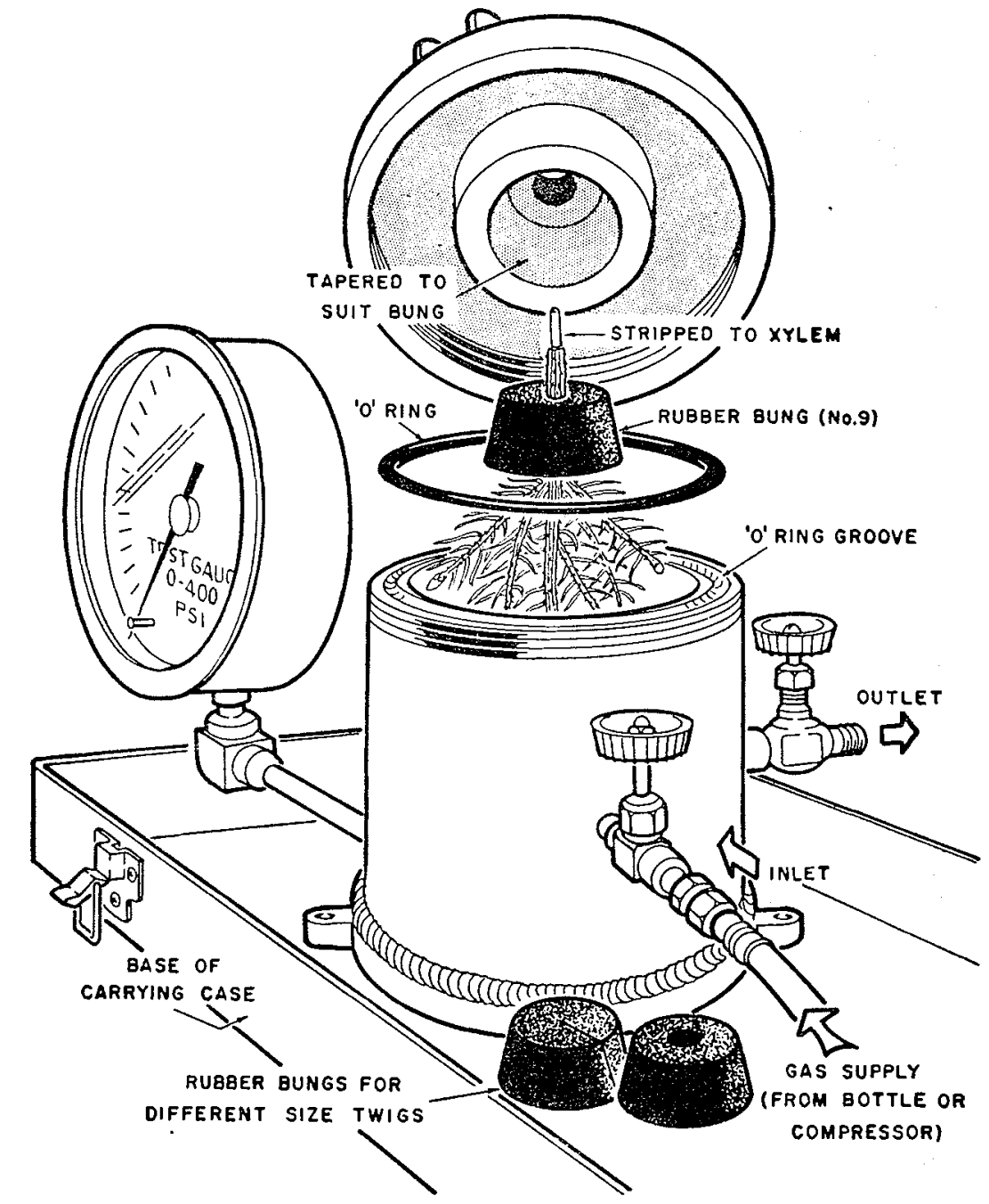

FIGURE 1. Plant pressure bomb. 
holder in the lid and tightens the lid onto the body of the bomb. The twig is now held inside the bomb with the cut end protruding. The cut end of the stem is observed closely through a hand-lens as the gas pressure is increased until the moisture is seen to wet the severed surface. The pressure is then recorded.

The method is quite sensitive. Under good conditions the cut surface can be seen to darken, as the moisture is brought back to the surface, before any water is actually expelled from the xylem under the next pressure increment, which might be as low as one or two pounds per square inch. Resin is usually expelled at lower gas pressures, but does not interfere unduly with the observations.

Results AND Discussion

Table 1 shows night-time values of internal moisture pressure obtained from seedlings in a growth chamber after 7 hours' darkness at $55^{\circ} \mathrm{F}$. and $85 \%$ relative humidity (daytime environment, $70^{\circ} \mathrm{F} ., 60 \%$ R.H.) related to various soil moisture conditions. The trees were in undisturbed portions of seedbeds, lifted dormant from nursery at $2-0$, now in third year of growth. Moisture pressure determinations were made on whole seedlings, severed above the root collar.

TABLE 1

Internal Moisture Pressure of Seedlings in Growth Chamber in Relation to Soll Moisture Potential

\begin{tabular}{lll}
\hline \multicolumn{1}{c}{ Species } & $\begin{array}{c}\text { Soil Moisture } \\
\text { Potential } \\
\text { atmos. approx. }\end{array}$ & $\begin{array}{c}\text { Plant Moisture } \\
\text { Pressure } \\
\text { n.s.i. }\end{array}$ \\
\hline Pinus resinosa & -0.06 (field capacity) & -90 \\
& -4.0 & -295 \\
Picea glauca & -15.0 (permanent wilting point) & lower than -380 \\
& -0.06 & -60 \\
& -4.0 & -200 \\
Larix laricina & -6.0 & -225 \\
& -0.06 & -260 (tree wilted) \\
& -0.3 & -70 \\
& -15.0 & -110 \\
& & lower than -380 \\
& & (tree wilted) \\
\hline
\end{tabular}

Table 2 shows summer daytime (early afternoon) values of internal moisture pressure and associated soil moisture and atmospheric conditions obtained from a fully-stocked plantation of 28-year-old Pinus resinosa growing on dry, medium-fine sand in Simcoe County, Southern Ontario. Moisture pressure determinations were made on second-order, mid-crown branches, both shaded and in full sun, immediately after severance. The first pair of determinations were made on two adjacent twigs from the same branch, one immediately after severance, the other after a deliberate delay of 12 minutes. Soil moisture contents were determined with a neutron probe. Total soil water at field capacity in the $0^{\prime \prime}-48^{\prime \prime}$ layer is approximately 6 inches.

It should be stressed that the results presented are typical of many values collected and have been selected to suggest several facts. 
TABLE 2

Internal Moisture Pressure of 28-year-old Pinus resinosa Trees in RElation to SOIL MOISTURe aNd ATMOSPHERIC CONDITIONS

\begin{tabular}{|c|c|c|}
\hline $\begin{array}{l}\text { Total Soil Water, inches, } \\
\text { (0 } \\
\text { (0'-48" 1ayer) and } \\
\text { Atmospheric Conditions }\end{array}$ & $\begin{array}{c}\text { Twig } \\
\text { Characteristics }\end{array}$ & $\begin{array}{l}\text { Plant Moisture } \\
\text { Pressure } \\
\text { p.s.i. }\end{array}$ \\
\hline 5.38 & Immediate value & -140 \\
\hline Hazy, cool, calm & 12 mins. delay & -180 \\
\hline 4.60 & Shaded & -190 \\
\hline Sunny, warm, light breeze & Sundit & -290 \\
\hline 3.08 & Shaded & -230 \\
\hline Sunny, warm, mod, breeze & Sunlit & -275 \\
\hline
\end{tabular}

First, internal moisture pressures were lower (numerically higher, but negative) than was originally expected from a consideration of soil moisture potential value. For example, the highest values read were only approximately minus 4 atmospheres, even with small seedlings in moist soil (of potential approximately - 0.06 atmospheres) at the end of a cool, humid night recovery period. Twigs cut from branches in higher positions on older trees could be expected to show lower values due to a hydrostatic gravity gradient whose value would be 0.1 atmosphere per meter (Scholander et al. 1965).

Second, although a soil moisture potential of -15 atmospheres $(-220$ p.s.i.) is considered to prevail at the so-called "permanent wilting point" of soil, internal moisture pressures fall below this value long before the foliage wilts.

Third, it is rather clear that, in a general way, internal moisture pressures decrease as soil moisture supplies are reduced, although the values depend on the tree species involved and on the local environment around the foliage (e.g. shaded twigs versus twigs in direct sunlight). Work remains to be done in determining the best sampling method based on studies of diurnal variation and spatial variation of the internal moisture pressure of larger trees. Waring and Cleary (1967) have contributed to this already.

Fourth, the determination of the internal moisture pressure of the sample should be made quickly, because the severed portion continues to transpire, causing a decrease of moisture pressure in the sample. Fortunately, determinations take only a minute or two.

Measurements of internal moisture pressure will not necessarily, render obsolete the measurement of soil moisture content or potential as a means of determining the supply of water currently available to a tree. However, the ability to measure this internal parameter opens wide the door to a more thorough understanding of tree growth processes in relation to moisture supply. It also provides a positive approach to certain management practices, the most obvious of which is the scheduling of nursery irrigation. Research scientist and forest manager alike should make full use of its possibilities.

\section{REFERENCES}

SCHOLANDER, P. F., HAMMEL, H. T., BRADSTREET, E. D. and E. A. HEMMINGSEN. 1965. Sap pressure in vascular plants. Science 148: 339-346.

WARING, R. H. and B. D. CLEARY. 1967. Plant moisture stress: evaluation by pressure bomb. Science 155: 1248-1254. 